\title{
Vertigo botanicorum sp. nov. (Gastropoda: Pulmonata: Vertiginidae)—a new whorl-snail from the Russian Altai Mountains
}

\author{
MICHAL HORSÁK ${ }^{1} \&$ BEATA M. POKRYSZKO ${ }^{2}$ \\ ${ }^{1}$ Department of Botany and Zoology, Faculty of Science, Masaryk University, Kotlářská 2, CZ-61137 Brno, Czech Republic. \\ E-mail:horsak@sci.muni.cz \\ ${ }^{2}$ Museum of Natural History, University of Wrocław, Sienkiewicza 21, 50-335 Wrocław, Poland. E-mail: bepok@biol.uni.wroc.pl
}

\begin{abstract}
Vertigo botanicorum sp. nov. is described from the Russian Altai Mountains. The species was recorded in 8 out of 118 study sites and totally 21 live individuals and 15 empty shells were collected. It is a medium-sized Vertigo species living in various tall-forb meadows, shrubby and forest habitats; avoiding only dry and strictly open sites. Mostly it was found in rather acidic sites of higher altitudes (above $1300 \mathrm{~m}$ a.s.l.).
\end{abstract}

Key words: Vertigo, terrestrial microgastropods, new species, southern Siberia, distribution, ecology

\section{Introduction}

The terrestrial snail genus Vertigo O.F. Müller, 1774 includes approximately 70 described living species distributed mainly throughout the Holarctic, with the global diversity centre of the genus in North America (see Nekola \& Coles 2010) and with ca. 30 species distributed in Eurasia (Pokryszko 2003; von Proschwitz 2007; Pokryszko et al. 2009; Sysoev \& Schileyko 2009). The members of this genus have ovoid to cylindrical shells that generally range between 1.5 and $3 \mathrm{~mm}$ in height and have a rounded aperture with $0-9$ lamellae at maturity.

Vertigo species of particular geographical and palaeontological interest have recently been found to be commonly distributed in Central Asia (Pokryszko \& Horsák 2007, Meng 2008, White et al. 2008, Horsák et al. 2010). Several of these are typical fossils in Central European glacial deposits and were previously known extant from only limited areas in Europe. In the course of ecological and palaeoecological research at 118 sites in the Russian Altai Mountains in August 2005 and July 2006, an undescribed species within the genus Vertigo was discovered.

Sites inventoried for snails were distributed along an approximately $300 \mathrm{~km}$-long NNW-SSE transect $\left(49^{\circ} 56^{\prime}-52^{\circ} 19^{\prime} \mathrm{N}, 85^{\circ} 35^{\prime}-88^{\circ} 31^{\prime} \mathrm{E}, 260-2570 \mathrm{~m}\right.$ a.s.l.), running across the Russian part of the Altai Mountains in the Altai Republic, a part of the Russian Federation, in southern Siberia (Fig. 1). The sites were selected to include the whole regional range of habitat types as determined by physiognomy and dominant plant species. Along the transect there is a steep climatic gradient of decreasing continentality from dry and cold conditions in the south-eastern part to relatively wet and warm conditions in the northern foothills (for details see Horsák et al. 2010). The wide climatic amplitude and range of habitat types of the sites studied make it possible to deliminate the new species' ecological requirements. For full locality information see Appendix 1. Further information on the study area and sites, sampling protocol and other methodologies are available in Horsák et al. (2010). All adult and undamaged shells $(\mathrm{n}=22)$ found at all eight sites were used for measurements and description of the conchological variability. Institutional abbreviations: DBZB-Department of Botany and Zoology, Masaryk University, Brno, Czech Republic; NMWP-Natural History Museum, Wrocław University, Wrocław, Poland; NMPC—National Museum, Prague, Czech Republic. 


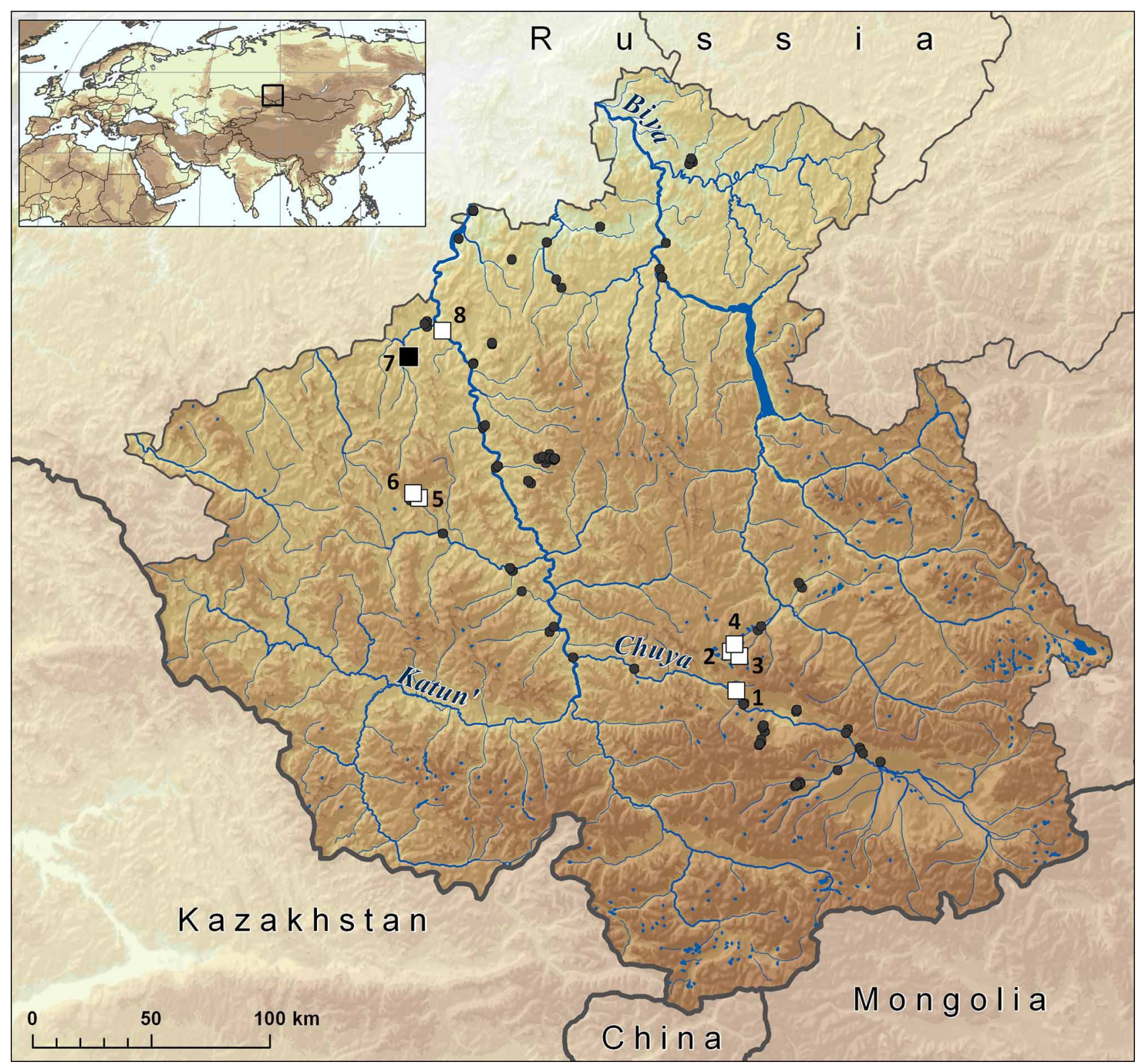

FIGURE 1. Map of the Altai Republic (Russia) with sampling sites. Squares—sites with Vertigo botanicorum sp. nov. (black square = type locality; for site numbers see App. 1); dots-sites without Vertigo botanicorum.

\section{Vertiginidae Pilsbry, 1918}

\section{Vertigo O.F. Müller, 1774}

Type species: Vertigo pusilla O.F. Müller, 1774 (monotypy)

\section{Vertigo botanicorum sp. nov.}

(Fig. 2)

Type locality. Loc. no. 7: 51³0'26.6”N, 85³5'48.6"E, Russian Altai Mts., Aktel: Seminski Ridge, Aktel creek valley, $4 \mathrm{~km}$ W of the settlement, 13 Aug. 2005, M. Horsák lgt.

Type material. Loc. no. 7: holotype and 1 paratype (NMWP), 2 paratypes (NMPC), 1 paratype (DBZB); Loc. no. 2: 6 paratypes (DBZB); Loc. no. 3: 2 paratypes (DBZB); Loc. no. 4: 1 paratype (DBZB); Loc. no. 6: 1 paratype (DBZB); Loc. no. 8: 1 paratype (DBZB). 
Other material examined. Loc. no. 1: 1 specimen; Loc. no. 4: 1 specimen; Loc. no. 3: 1 specimen; Loc. no. 2: 3 specimens (all in DBZB).
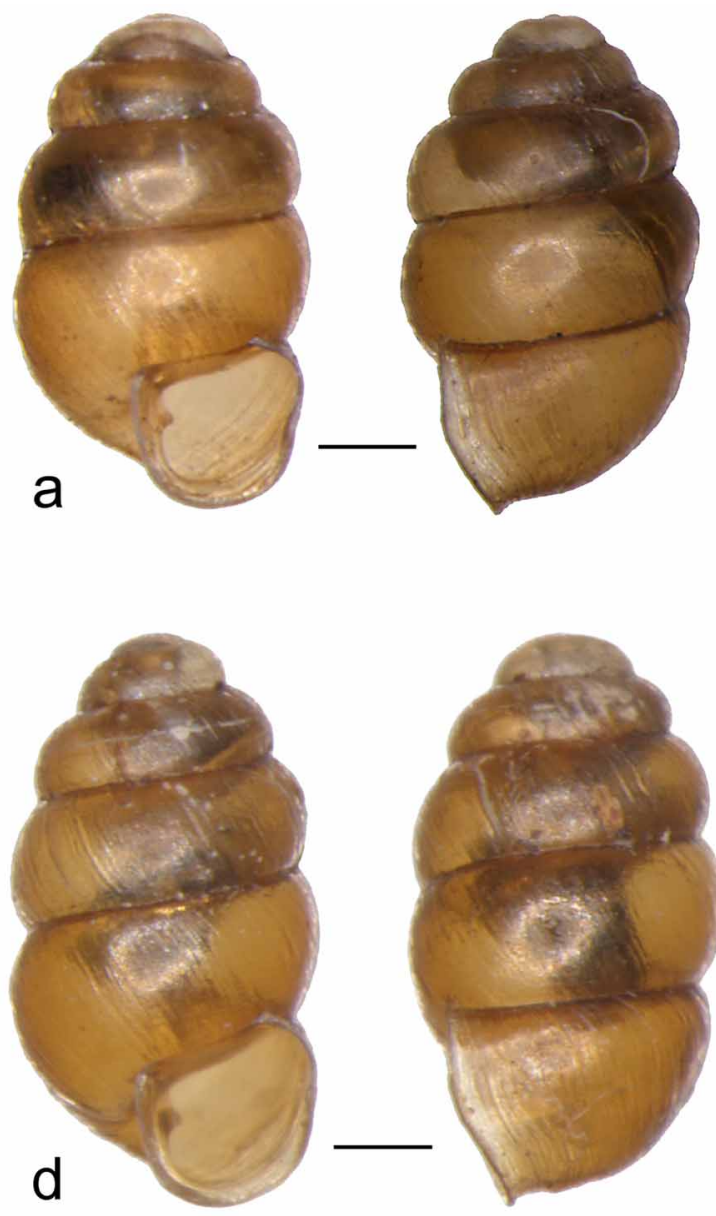

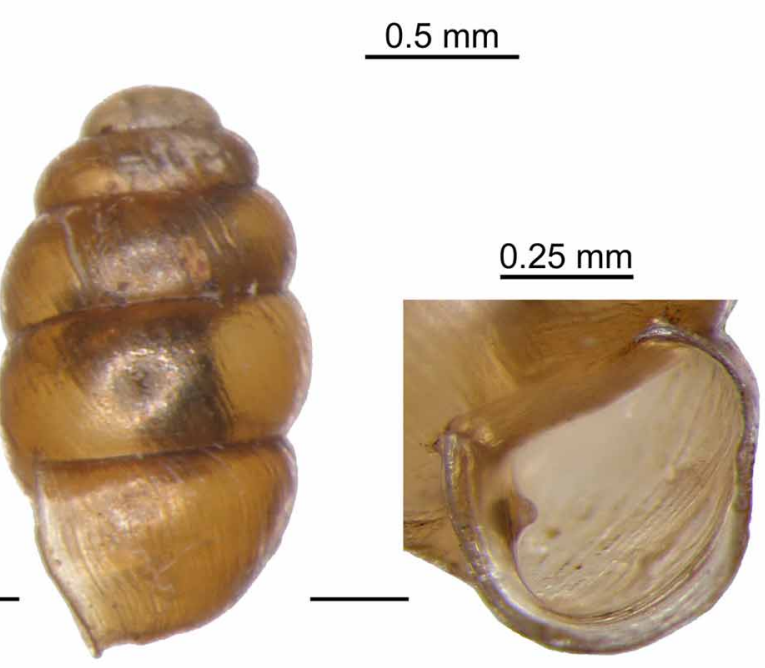

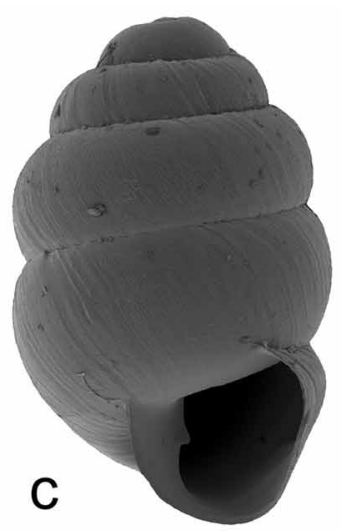
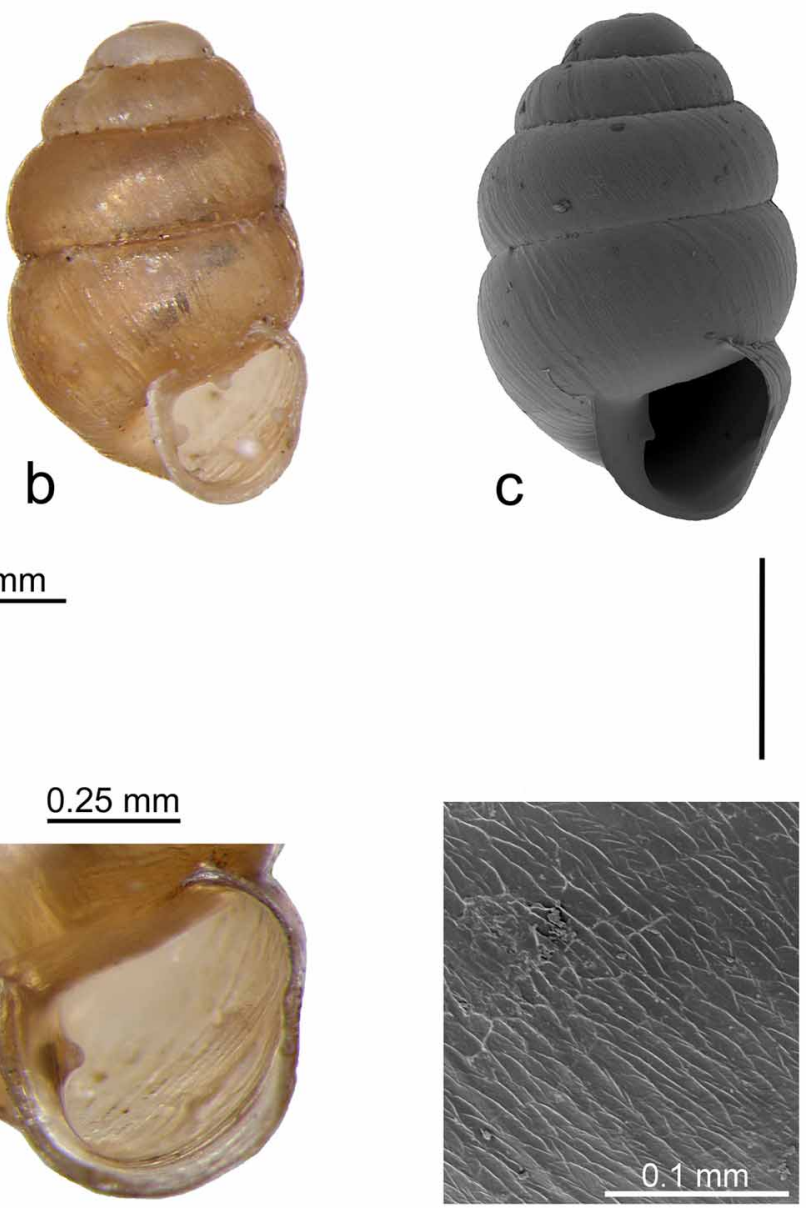

FIGURE 2. Vertigo botanicorum sp. nov. from the Altai Republic (Russia); a, Holotype, NMWP, Loc. no. 7 (see Appendix 1); b, Paratype, DBZB, Loc. no. 8; c, Paratype, DBZB, Loc. no. 7; d, Paratype, DBZB, Loc. no. 6. Photos by M. Horsák (a, b, d) and P. Kment (c).

Etymology. We dedicate this species to all the botanists who took part in the Altai expeditions: Milan Chytrý, Jiří Danihelka, Nikolai Ermakov, Michal Hájek, Petra Hájková, Martin Kočí, Svatava Kubešová, Pavel Lustyk, Zdenka Otýpková, Barbora Pelánková, and Milan Valachovič. Because of the efforts of these colleagues, the senior author had a remarkable field experience during the Altai Mountains expeditions, and was able to collect considerable field data of a high scientific value.

Description of the shell ( $\mathrm{n}=22$, Fig. 2). Shell dextral, height 1.78-2.25 mm (mean 1.98, SD 0.123, holotype 1.85), width $1.08-1.28 \mathrm{~mm}$ (mean 1.14, SD 0.056, holotype 1.10), aperture height $0.60-0.78 \mathrm{~mm}$ (mean 0.69, SD 0.059, holotype 0.63), aperture width 0.60-0.78 mm (mean 0.68, SD 0.043, holotype 0.65), body whorl height 1.03-1.23 mm (mean 1.12, SD 0.061, holotype 1.05), height/width ratio 1.51-2.00 (mean 1.74, SD 0.119, holotype 1.68), relative height of body whorl 0.50-0.62 (mean 0.57, SD 0.028, holotype 0.55), whorls 4.8-5.4 (mean 4.98, SD 0.16, holotype 4.8). Shell clearly ovate, the body whorl being distinctly broadest, with convex spire and gently rounded apex. Whorls not very convex with a shallow suture. Aperture semi-oval, with palatal margin slightly flattened or with a very shallow indentation. Lip narrow, very slightly thickened, in fresh shells of the same colour as the rest of the shell, narrowly but clearly reflexed on the columellar, basal and lower half of the palatal margin; parietal callus very weak, lip insertions almost not approaching. Aperture with 1-4 vestigial or very small lamellae with the columellar and palatal rather deeply set; all teeth tubercular and white, no trace of a palatal callus even in specimens with four lamellae; the holotype possesses a small columellar and vestigial parietal lamella. In side view the body whorl suture does 
not or only almost imperceptibly ascend. The outside of the palatal wall lacks a crest, and possesses only a shallow, indistinct furrow corresponding with the upper palatal (even in toothless shells). Shells with two lamellae have a columellar and parietal, shells with a single lamella may have either of the two. The umbilicus is oval and narrow. Shell semitransparent, light golden-brownish, in very fresh shells with a greasy sheen; surface almost completely devoid of growth lines and/or striation, only with the specific microstructure of subparallel, anastomosing periostracal ridges which is more pronounced than in other Vertigo species; the few growth lines, if present, are faint, almost invisible.

TABLE 1. List of co-occurring species in all eight sites with Vertigo botanicorum sp. nov., sites where they occurred (see Appendix 1) and total number of each species' records.

\begin{tabular}{lll}
\hline Co-occurring species & Sites & No. of Records \\
\hline Euconulus fulvus (O.F. Müller, 1774) & $1,3,4,5,6,7,8$ & 7 \\
Perpolita hammonis (Ström, 1765) & $1,2,3,5,6,7,8$ & 7 \\
Novisuccinea altaica (Martens, 1879) & $1,2,3,4,6$ & 5 \\
Vertigo microsphaera Schileyko, 1984 & $1,5,6,8$ & 4 \\
Deroceras altaicum (Simroth, 1886) & $4,6,7$ & 3 \\
Perpolita petronella (L. Pfeiffer, 1853) & $5,6,8$ & 3 \\
Pupilla muscorum (Linné, 1758) & $2,4,6$ & 3 \\
Columella intermedia Schileyko et Almuhambetova, 1984 & 4,5 & 2 \\
Pupilla loessica Ložek, 1954 & 2,4 & 2 \\
Vallonia costata (O.F. Müller, 1774) & 6,7 & 2 \\
Vallonia kamtschatica Likharev, 1963 & 1,2 & 2 \\
Cochlicopa lubrica (O.F. Müller, 1774) & 8 & 1 \\
Columella edentula (Draparnaud, 1805) & 1 & 1 \\
Fruticicola schrenkii (Middendorff, 1851) & 8 & 1 \\
Punctum pygmaeum (Draparnaud, 1801) & 8 & 1 \\
Vallonia ladacensis (Nevill, 1878) & 2 & 1 \\
Vertigo genesii (Gredler, 1856) & 4 & 1 \\
Vertigo parcedentata (Al. Braun, 1847) & 4 & 1 \\
Vertigo pseudosubstriata Ložek, 1954 & 4 & 1 \\
Vertigo pygmaea (Draparnaud, 1801) & 7 & 1 \\
Vitrina rugulosa Martens, 1874 & 6 & 1 \\
\hline
\end{tabular}

Comparative notes. The species appears to be a member of a basically northern group including Vertigo modesta (Say, 1824), V. ronnebyensis (Westerlund, 1871), V. ultimathule von Proschwitz, 2007, V. extima (Westerlund, 1877) and some North American members of the V. modesta clade, especially V. modesta hoppii (Möller, 1842), V. cristata (Sterki, 1919), V. coloradensis (Cockerell, 1891), and the undescribed "Vertigo AK 2" (see Nekola et al. 2009, Nekola \& Coles 2010). It is also conchologically similar to V. parcedentata (Al. Braun, 1847) and V. nangaparbatensis Pokryszko et Hlaváč, 2009. It differs from V. modesta, which it resembles in shell shape and dentition pattern, in lighter colour ( $V$. modesta is chestnut-reddish), smaller size (ca. 2/3 height and width), sheen (fresh $V$. modesta glossy, as if wet) and much smoother shells (in $V$. modesta clear and rather regular though delicate striae are present). It differs from $V$. ronnebyensis mainly in surface structure; V. ronnebyensis has fine regular ribs, spire striation and more cylindrical shape. Vertigo botanicorum sp. nov. differs from V. ultimathule and V. extima in weaker striation and much more pronounced microscopic periostracal ridges of the surface, less convex whorls with shallower suture, smaller size (especially from V. extima) and more ovate shape. It differs from conchologically similar North American species in its microsculpture (Fig. 2c) and the absence of regular small ribs. In addition, both V. coloradensis 
and V. cristata possess a marked crest and much stronger lamellae (especially palatal), V. modesta hoppii has a darker, chestnut-red shell with a glossy sheen and weak crest, while "Vertigo AK 2" has pronounced shell striation and often a weakly developed crest that somewhat narrows the aperture. Vertigo botanicorum sp. nov. resembles the syntopic $V$. parcedentata in shell shape, colour and dentition, but it differs in being somewhat smaller, having a shallower suture and less convex whorls, by possessing a matte sheen (fresh $V$. parcedentata is glossy as if wet), being more oval (V. parcedentata is often somewhat cylindrical), and having pronounced microscopic periostracal ridges. It also differs from $V$. nangaparbatensis in being smaller, more ovate, more tumid, having poorly developed dentition and much more pronounced microscopic periostracal ridges (Fig. 2c). This characteristic microsculpture is also developed in other sympatric Vertigo species, such as V. pygmaea (Draparnaud, 1801), V. substriata (Jeffreys, 1833) and V. microsphaera Schileyko, 1984, which differ in many external features and the apertural barriers. However, no studies of this microsculpture have been conducted and its phylogenetic relevance is completely unknown.

Ecology. This new species has a rather broad ecological amplitude. It was found in different mesic and wet habitats such as hemiboreal forests, subalpine shrub vegetation, and mostly shrubby meadow steppes (Festuco-Brometea). It avoided only strictly open and dry sites. This snail occurred along a relatively broad range of site basicity (topsoil electric conductivity 33-164 $\mu \mathrm{S} / \mathrm{cm}$ and $\mathrm{pH}$ 5.4-6.7). Like V. modesta hoppii from North America (Nekola \& Coles 2010), V. botanicorum sp. nov. was mostly found in rather acidic sites and avoided calcareous substrates. Most sites were at high altitudes (above $1350 \mathrm{~m}$ a.s.1.), but occurred also at two rather low sites (around $500 \mathrm{~m}$ a.s.l., see Appendix 1). Population densities were intermediate or low, varying from 1 to 10 recorded specimens per site. All species co-occurring with V. botanicorum sp. nov. at the studied sites are given in Table 1. Euconulus fulvus (O.F. Müller, 1774), Perpolita hammonis (Ström, 1765), Novisuccinea altaica (Martens, 1879) and Vertigo microsphaera were the species most often co-occurring with the species described here (Tab. 1).

\section{Acknowledgements}

We thank Petr Kment for his help with SEM photographs and Ondřej Hájek for preparing the map. We are very grateful to Jeff Nekola, who made several useful comments and important linguistic improvements to a previous version, and to the second, anonymous referee. This research was funded by the Ministry of Education of the Czech Republic (MSM0021622416) and the Academy of Sciences of the Czech Republic (IAA6163303, AVOZ60050516).

\section{References}

Horsák, M., Chytrý, M., Pokryszko, B.M., Danihelka, J., Ermakov, N., Hájek, M., Hájková, P., Kintrová, K., Kočí, M., Kubešová, S., Lustyk, P., Otýpková, Z., Pelánková, B., Valachovič, M. (2010) Habitats of relict terrestrial snails in southern Siberia: lessons for the reconstruction of palaeoenvironments of full-glacial Europe. Journal of Biogeography, 37, 1450-1462.

Meng, S. (2008) Neue Daten zur Verbreitung der Vertiginidae (Gastropoda: Pulmonata) in Zentralasien. Mollusca, 26, 207-219.

Nekola, J. \& Coles, B.F. (2010) Pupillid land snails of eastern North America. American Malacological Bulletin, 28, 2957.

Nekola, J., Coles, B.F. \& Bergthorsson, U. (2009) Evolutionary pattern and process within the Vertigo gouldii (Mollusca: Pulmonata, Pupillidae) group of minute North American land snails. Molecular Phylogenetics and Evolution, 53, 1010-1024.

Pokryszko, B.M. (1993) Fen malacocenoses in Dovrefjell (S. Norway). Fauna Norvegica, Series A, 14, $27-38$.

Pokryszko, B.M. (2003) Vertigo of continental Europe-autecology, threats and conservation status (Gastropoda, Pulmonata: Vertiginidae). Heldia, 5/7, 13-25.

Pokryszko, B.M., Auffenberg, K., Hlaváč, J.Č. \& Naggs, F. (2009) Pupilloidea of Pakistan (Gastropoda: Pulmonata): Truncatellininae, Vertigininae, Gastrocoptinae, Pupillinae (in part). Annales Zoologici (Warszawa), 59, 423-458.

Pokryszko, B. \& Horsák, M. (2007) Pupilloidea (Pupillidae, Vertiginidae, Valloniidae, Gastrocoptinae) of the Altay-a 
travel in space and time, In: Jordaens, K., Van Houtte, N., Van Goethem, J. \& Backeljau, T. (Eds) World Congress of Malacology, Antwerp, Belgium, 15-20 July 2007, Abstracts. Unitas Malacologica, Antwerp, p. 170.

Proschwitz, T. von (2007) Vertigo ultimathule n. sp., a new whorl-snail from northernmost Sweden (Gastropoda: Pulmonata: Vertiginidae). Heldia, 5, 73-74., pl. 9.

Sysoev, A. \& Schileyko, A. (2009) Land snails and slugs of Russia and adjacent countries. Pensoft, Sofia-Moscow, 312 pp., 142 pls.

White, D., Preece, R.C., Shchetnikov, A.A., Parfitt, S.A. \& Dlussky, K.G. (2008) A Holocene molluscan succession from floodplain sediments of the upper Lena River (Lake Baikal region), Siberia. Quaternary Science Reviews, 27, 962987.

Appendix 1. Account of studied sites in the Russian Altai Mountains with the occurrence of Vertigo botanicorum sp. nov. Data in the list are arranged as follows: site number (bold, corresponds with the map); original site number (in square brackets) for easier reference to databases, geographical co-ordinates (N, E); district; location; habitat description; altitude (m a.s.1.); collection date; number of recorded specimens. All sites were investigated by M. Horsák.

1 [MC210]; 50 $18^{\prime} 03.3^{\prime \prime} \mathrm{N} ; 87^{\circ} 38^{\prime} 59.7^{\prime \prime} \mathrm{E}$; Ulagan distr.; Aktash: above the right bank of the Menka river $4 \mathrm{~km}$ ESE of the village; hemiboreal forest with Picea obovata on a steep N-facing slope; $1397 \mathrm{~m} ; 20$.vii.2006; 2 specimens. 2 [MC209]; 50²6'50.0"N 87 $^{\circ} 36^{\prime 2} 28.1^{\prime \prime} \mathrm{E}$; Ulagan distr.; Aktash: near the road to Ulagan $16 \mathrm{~km} \mathrm{~N}$ of the town, south of the Ulagan pass; species-rich grassland on a steep slope; $1976 \mathrm{~m}$; 19.vii.2006; 10 specimens; data published in Horsák et al. (2010). 3 [MC208]; 50³2'49.9'N; 8747'05.1"E; Ulagan distr.; Ulagan: near the road to Aktash 16 km $\mathrm{SW}$ of the village; species-rich grassland; $1615 \mathrm{~m} ; 19 . v i i .2006 ; 3$ specimens. 4 [PL201]; 50 ${ }^{\circ} 28^{\prime} 36.0^{\prime \prime} \mathrm{N}$; 87³7'48.4"E; Ulagan distr.; Ulagan: plateau near Uzunkel' lake $28 \mathrm{~km} \mathrm{SW}$ of the village; shrubby tundra dominated by Betula humilis and Betula rotundifolia; 1994 m; 18.vii.2006; 2 specimens; data published in Horsák et al. (2010). 5 [MC149]; 5059'05.5'N; 8540'32.4"E; Ongudai distr.; Zaisanskaya Elan' (S of Seminskii pereval): Seminskii Ridge, above right bank of Tuekta creek $2 \mathrm{~km} \mathrm{NW}$ of the settlement; taiga with Picea obovata and Pinus sibirica on a gentle NNE-facing slope; $1382 \mathrm{~m}$; 12.viii.2005; 5 specimens. 6 [MC152]; 5059'30.9'N; 8540'18.8' E; Ongudai distr.; Zaisanskaya Elan' (S of Seminskii pereval): Seminskii Ridge, above left bank of Tuekta creek near a road bridge $2 \mathrm{~km} \mathrm{NW}$ of the settlement; hemiboreal forest with Larix sibirica on a gentle SE-facing slope; $1397 \mathrm{~m}$; 12.viii.2005; 1 specimen. 7 [PH144] Type locality; 51³0'26.6"N; 85³5'48.6”'E; Shebalino distr.; Aktel: Seminski Ridge, Aktel creek valley, $4 \mathrm{~km}$ W of the settlement; tall-forb meadow in a floodplain, dominated by Filipendula ulmaria and Trollius altaicus; 575 m; 13.viii.2005; 7 specimens. 8 [MC101]; 51 ${ }^{\circ} 36^{\prime} 47.7^{\prime \prime} \mathrm{N}$; 85 47'32.5'E; Chemal distr.; Katun' valley, Ust'-Sema: left bank of the Katun' river $1 \mathrm{~km}$ SE of the village; Pinus sylvestris forest with Pteridium aquilinum and Brachypodium pinnatum; $360 \mathrm{~m} ; 30 . v i i .2005 ; 6$ specimens. 